\title{
An Attempt to Establish the Variables That Most Directly Influence the Austenite Formation Process in Steels
}

\author{
F. G. CABALLERO, C. CAPDEVILA and C. GARCÍA DE ANDRÉS
}

Department of Physical Metallurgy, Centro Nacional de Investigaciones Metalúrgicas (CENIM), CSIC, Avda. Gregorio del Amo, 8, 28040 Madrid, Spain. E-mail: cgda@cenim.csic.es

(Received on February 12, 2002; accepted in final form on December 18, 2002)

\begin{abstract}
The aim of this work is to evaluate the influence of heating rate and initial microstructure on the anisothermal formation of austenite. In this sense, the start $\left(A c_{1}\right)$ and finish $\left(A c_{3}\right)$ temperatures of austenite formation have been determined on dilatometric curves obtained at various heating rates in steels with ferrite and/or pearlite initial microstructures. As it was expected, $A c_{1}$ and $A c_{3}$ temperatures rises linearly with heating rate, except for steels with a pure ferrite initial microstructure where the $A c_{1}$ temperature is almost insensitive to heating rate over the range studied. Experimental results in steels with a pearlite and ferritepearlite initial microstructures also show that the elevation of the critical temperatures with heating rate is quite sensitive to the morphology of pearlite. It seems that the higher the heating rate is, the stronger the influence of morphology on the critical temperatures are. This experimental study and the knowledge of the mechanisms that control the austenite formation process have allowed to establish the variables that most directly influence this reaction in steels with pearlite and ferrite-pearlite initial microstructures. Those are the heating rate and the two parameters that characterise the morphology of pearlite, the mean true interlamellar spacing and the edge length of the pearlite colonies interface in pearlitic steels, together with the volume fraction of pearlite and the mean free distance of pearlite in ferrite plus pearlite initial microstructures. Likewise, two equations have been proposed for the determination of the start $\left(A c_{1}\right)$ and $\left(A c_{3}\right)$ finish temperatures of austenite formation as a function of those variables.
\end{abstract}

KEY WORDS: heating critical temperatures; austenite formation; steels.

\section{Introduction}

The formation of austenite during heating differs in many ways from those transformations that occur during the cooling of austenite. For instance, the kinetics of austenite decomposition can be described completely in terms of the chemical composition and the austenite grain size. By contrast, the microstructure from which austenite may form is more complex and additional variables are therefore needed to describe the kinetics of austenite formation. Factors such as particle size, distribution and chemistry of individual phases, homogeneity and the presence of non-metallic inclusions should all be important. ${ }^{1-4)}$ Thus, in the case of formation of austenite from pearlite, the most relevant structural factor to be considered is the interlamellar spacing of pearlite. ${ }^{5)}$

The development of dual-phase steels by partial austenitisation revived the interest for the heating part of the heat treatment cycle in the eighties. Dual-Phase steels, widely used in the automobile industry, are characterised by a superior combination of mechanical properties. These steels are produced by annealing low carbon steels in the intercritical temperature range with the aim of obtaining ferriteaustenite mixtures, and subsequent quenching to transform the austenite phase into martensite. ${ }^{6-8)}$ Speich et al. ${ }^{2)}$ and, Garcia and DeArdo ${ }^{1)}$ described in detail the mechanisms that control the austenite formation process under isother- mal conditions in low carbon steels with a ferrite-pearlite initial microstructure. Later, Roosz et $a l^{9)}$ quantitatively determined the influence of the initial microstructure on the nucleation rate and grain growth of austenite during isothermal treatment of an eutectoid plain carbon steel. All these reports emphasised the importance of the microstructure that exists before intercritical annealing.

However, little information is available about the austenite formation in steels subjected to continuous heating. Recently, some researchers have adopted a new approach to the problem using artificial neural network. ${ }^{10,11)}$ This has helped to identify the fact that a neglect of the starting microstructure can lead to major errors in the transformation temperatures, sometimes by more than $100^{\circ} \mathrm{C}$. In this sense, the aim of this work is to evaluate the influence of heating rate and microstructural parameters such as interlamellar spacing of pearlite and the mean free distance of pearlite on the anisothermal formation of austenite in steels with initial microstructures consisting of ferrite and/or pearlite. This study will allow to establish the variables that most directly influence the austenite formation process and to propose two empirical formula for the determination of the start $\left(A c_{1}\right)$ and finish $\left(A c_{3}\right)$ temperatures of austenite formation as a function of those variables. 


\section{Experimental Procedure}

Table 1 lists the chemical composition of the studied steels. FERR steel in Table 1 has a full ferrite initial microstructure as shown in Fig. 1. Specimens of this steel were ground and polished using standardised techniques for metallographic examination. Nital-2pct etching solution was used to reveal the ferrite microstructure by optical microscopy. The ferrite grain size was measured on micrographs. An average ferrite grain diameter $(D)$ of $158 \mu \mathrm{m}$ was estimated by counting the number of grains intercepted by one or more straight lines long enough to yield at least fifty intercepts in total. The effect of a moderately nonequiaxial microstructure was eliminated by counting the intersections of lines in four or more orientations covering all the observation fields with an approximately equal weight. ${ }^{12)}$

The following heat treatments were carried out to yield in PEARL steel (Table 1) fully pearlitic microstructures with different scale parameters. Specimens were austenitised for $5 \mathrm{~min}$ at $1000^{\circ} \mathrm{C}$, isothermally transformed at one of two different temperatures and subsequently cooled rapidly to room temperature. Table 2 lists the temperatures and holding times used for the isothermal formation of pearlite with different morphological parameters in this

Table 1. Chemical composition (mass $\%$ ).

\begin{tabular}{ccccccccc}
\hline Steels & $\mathrm{C}$ & $\mathrm{Mn}$ & $\mathrm{Si}$ & $\mathrm{N}$ & $\mathrm{Al}$ & $\mathrm{P}$ & $\mathrm{Cr}$ & $\mathrm{Ni}$ \\
\hline FERR & 0.002 & 0.05 & - & 0.004 & - & 0.003 & - & - \\
PEARL & 0.76 & 0.91 & 0.24 & - & - & 0.013 & - & - \\
MIXT & 0.11 & 0.50 & 0.028 & 0.004 & 0.046 & 0.015 & 0.012 & 0.020
\end{tabular}

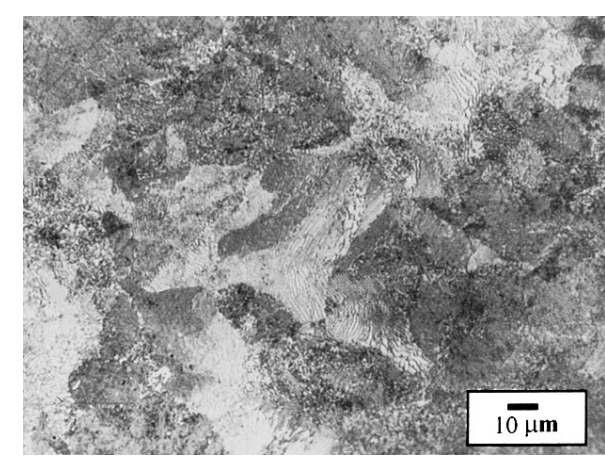

(a)

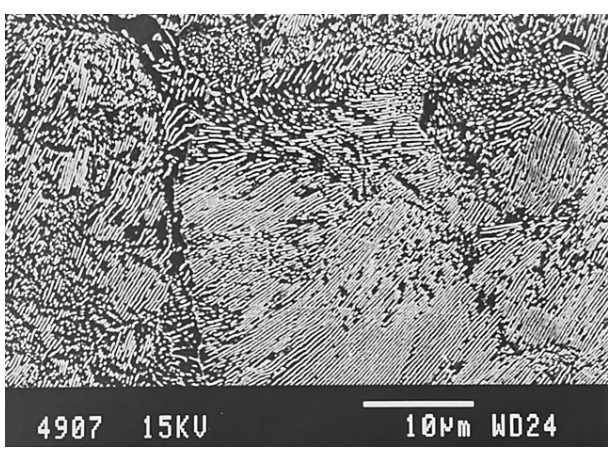

(c) steel. Specimens were ground and polished using standardised techniques and finished on $0.25 \mu \mathrm{m}$ diamond paste for metallographic examination. 2 pct-Nital etching solution was used to reveal the microstructure by light optical microscopy (LOM). Micrographs in Figs. 2(a) and 2(b) confirm that $100 \%$ transformation to pearlite occurs at both heat treatments performed (Table 2). An etching solution of

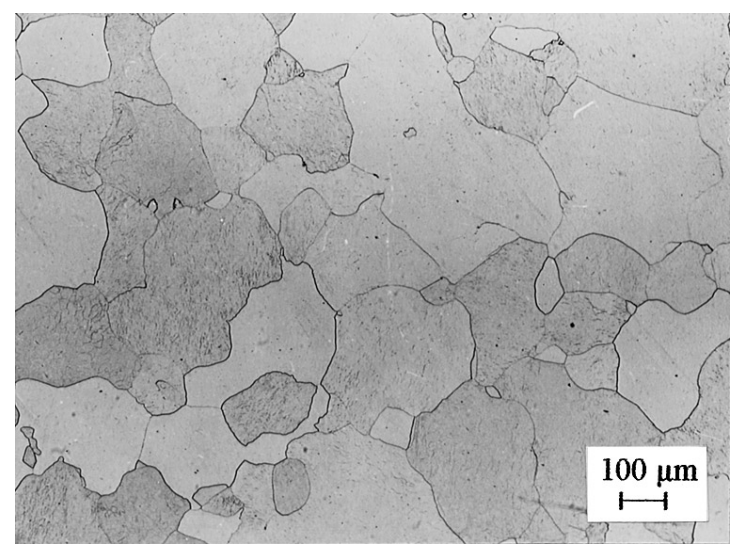

Fig. 1. Optical micrograph of initial microstructure in FERR steel.

Table 2. Isothermal conditions employed for the formation of pearlite microstructures in PEARL steel.

\begin{tabular}{ccc}
\hline Specimen & $\begin{array}{c}\text { Temperature } \\
\left({ }^{\circ} \mathrm{C}\right)\end{array}$ & $\begin{array}{c}\text { Time } \\
(\mathrm{min})\end{array}$ \\
\hline PEARL1 & 675 & 45 \\
PEARL2 & 525 & 60 \\
\hline
\end{tabular}

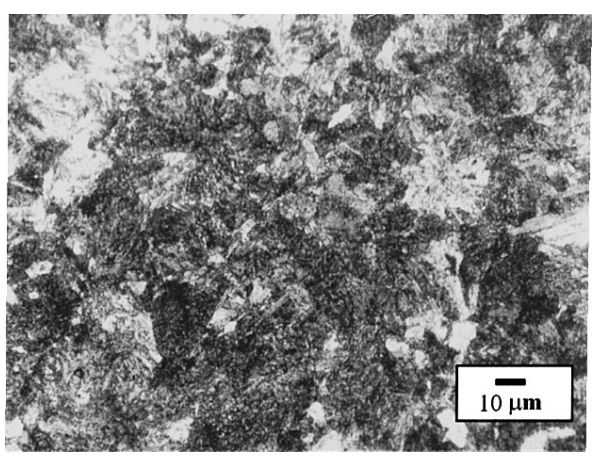

(b)

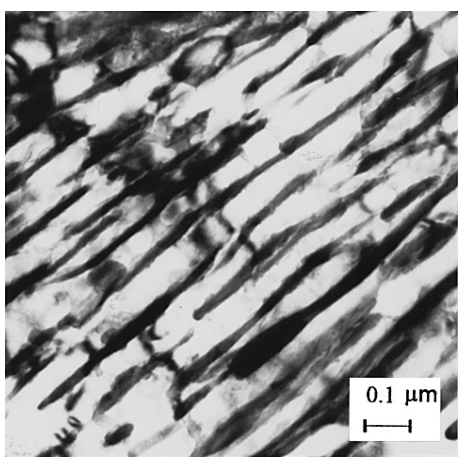

(d)

Fig. 2. Optical and electron micrographs of the two different morphologies of pearlite in PEARL steel (Table 2): (a) PEARL1 (LOM); (b) PEARL2 (LOM); (c) PEARL1 (SEM); and (d) PEARL2 (TEM). 
picric acid in isopropyl alcohol with several drops of Vilella's reagent was also used to reveal pearlite in PEARL1 specimen on a JEOL JXA-820 scanning electron microscope (SEM) (Fig. 2(c)). Pearlite in PEARL2 specimen was characterised by transmission electron microscopy (TEM). For this, $3 \mathrm{~mm}$ diameter cylindrical samples were sliced into $100 \mu \mathrm{m}$ thick discs and subsequently ground down to foils of $50 \mu \mathrm{m}$ thickness on wet 800 grit silicon carbide paper. These foils were finally electropolished at room temperature until perforation occurred, using a twinjet electropolisher set (E. A. Fischione Inst. Mfg-Model 110 ) at a voltage of $100 \mathrm{~V}$. The electrolyte consisted of $5 \%$ perchloric acid, $15 \%$ glycerol and $80 \%$ methanol. The foils were examined in a JEOL JEM-200 CX transmission electron microscope (TEM) at an operating voltage of $200 \mathrm{kV}$. (Fig. 2(d)).

MIXT steel in Table 1 is a low carbon-low manganese steel with a ferrite plus pearlite initial microstructure. Semi rolled slabs $36 \mathrm{~mm}$ thick were soaked at $1250^{\circ} \mathrm{C}$ for $15 \mathrm{~min}$, hot rolled to $6 \mathrm{~mm}$ in several passes, and finally air cooled to room temperature. Specimens of this steel were

Table 3. Continuous cooling conditions employed for the formation of ferrite and pearlite microstructures in MIXT steel.

\begin{tabular}{ccc}
\hline Specimen & Microstructure & $\begin{array}{c}\text { Cooling Rate } \\
\left({ }^{\circ} \mathrm{C} / \mathrm{s}\right)\end{array}$ \\
\hline MIXT1 & As-rolled & - \\
MIXT2 & As-annealed & 0.5 \\
MIXT3 & As-annealed & 0.1 \\
MIXT4 & As-annealed & 0.05 \\
\hline
\end{tabular}

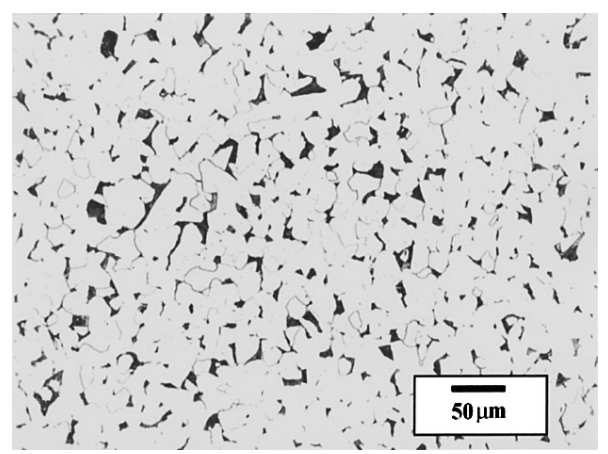

(a)

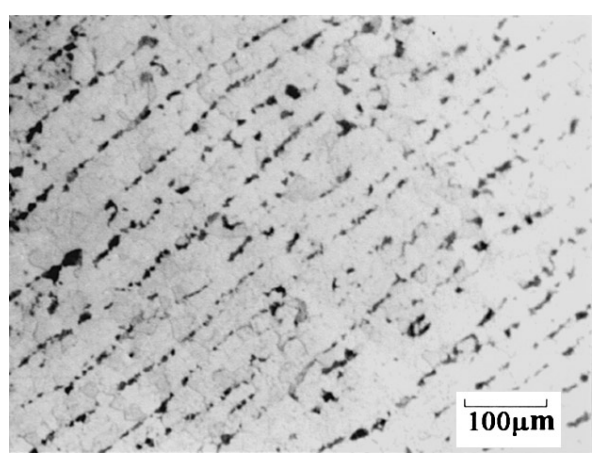

(c) reheated to $1000^{\circ} \mathrm{C}$, held for $60 \mathrm{~s}$ and cooled at one of three different cooling rates to obtain three ferrite and pearlite starting microstructures with different morphology of pearlite (MIXT2 $\rightarrow 4$ ). Table 3 lists the cooling rates used for the formation of ferrite and pearlite with different morphological parameters in this steel. As-rolled and annealed resultant microstructures all are formed by, approximately, $89 \%$ of ferrite and $11 \%$ of pearlite (Fig. 3). Specimens were polished in the usual way and finished on $0.5 \mu \mathrm{m}$ diamond paste for metallographic examination. Two types of etching solution were used: Nital-2pct to reveal the ferrite-pearlite microstructure by light optical microscopy and solution of picric acid in isopropyl alcohol with several drops of Vilella's reagent to disclose the pearlite morphology on a JEOL JXA 840 scanning electron microscope. Figure 4 shows the scanning micrograph of all the different morphologies of pearlite considered for MIXT steel.

Two parameters, the mean true interlamellar spacing, $\sigma_{o}$, and the area per unit volume of the pearlite colonies interface, $S_{\mathrm{v}}^{\mathrm{PP}}$, characterise the morphology of pearlite. ${ }^{9)}$ The values of $\sigma_{\mathrm{o}}$ in all the cases (PEARL1-2 and MIXT1-4 specimens) were derived from electron micrographs according to Underwood's intersection procedure. ${ }^{13,14)}$ The values of $S_{\mathrm{v}}^{\mathrm{PP}}$ were measured on scanning micrographs by counting the number of intersections of the pearlite colony boundaries with a circular test grid as reported by Roosz et $a l .{ }^{9)}$ Approximating the pearlite colony by a truncated octahedron, the edge length of the pearlite colonies, $a^{\mathrm{P}}$, is calculated from the area per unit volume, $S_{\mathrm{v}}^{\mathrm{PP}}$, with the following expression ${ }^{15)}$ :

$$
S_{\mathrm{v}}^{\mathrm{PP}}=\frac{6(1+2 \sqrt{3})\left(a^{\mathrm{P}}\right)^{2}}{8 \sqrt{2}\left(a^{\mathrm{P}}\right)^{3}}=\frac{3(1+2 \sqrt{3})}{2 \sqrt{2} a^{\mathrm{P}}}
$$

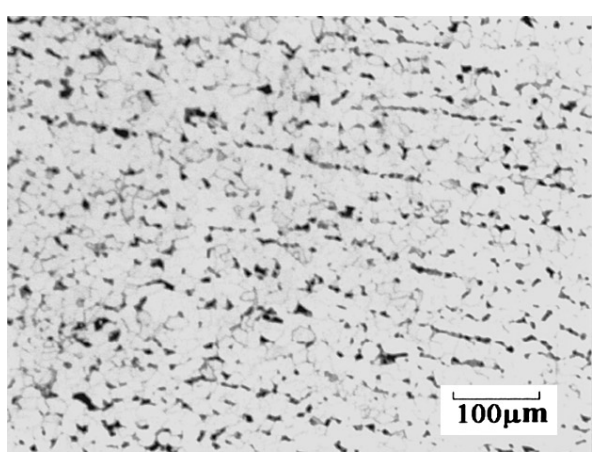

(b)

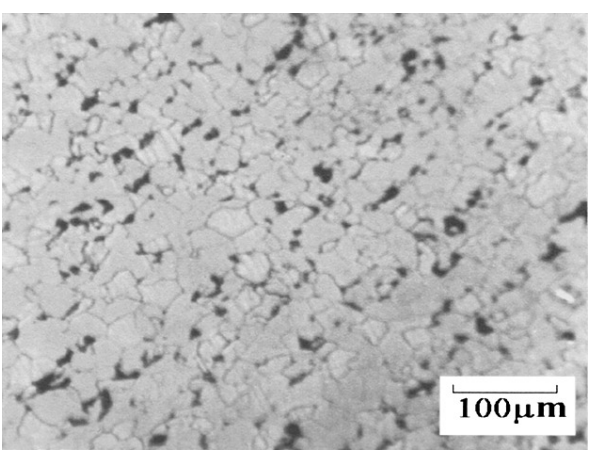

(d)

Fig. 3. Optical micrograph of the four different initial microstructures considered in MIXT steel (Table 3): (a) MIXT1, (b) MIXT2, (c) MIXT3 and (d) MIXT4 


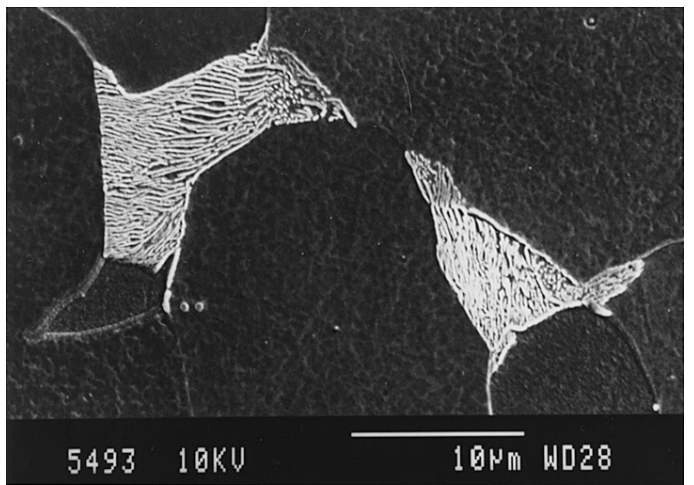

(a)

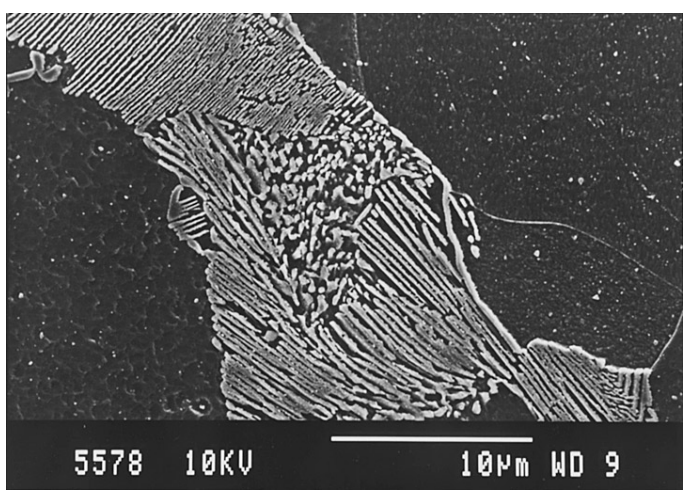

(c)

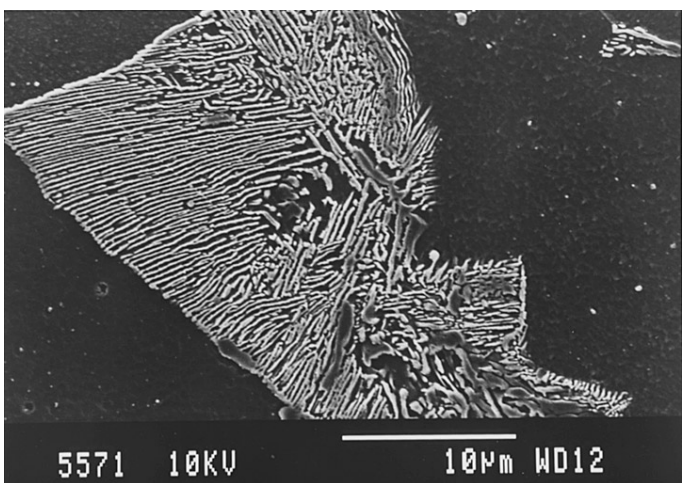

(b)

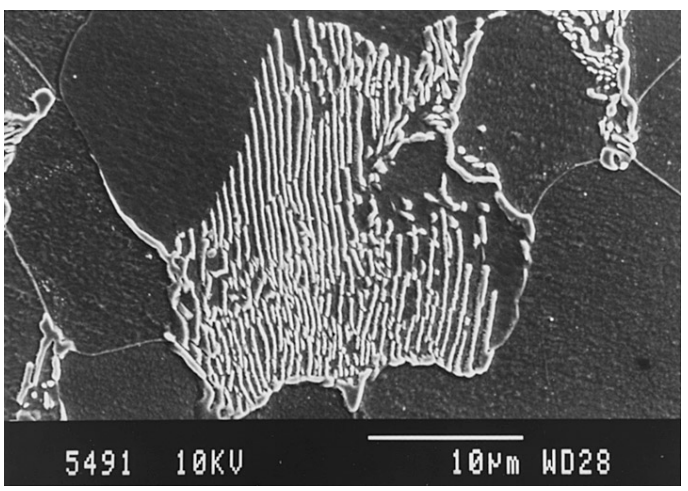

(d)

Fig. 4. Scanning micrograph of the four different morphologies of pearlite considered in MIXT steel (Table 3): (a) MIXT1, (b) MIXT2, (c) MIXT3 and (d) MIXT4.

Table 4. Morphological characterisation of pearlite in PEARL steel.

\begin{tabular}{cccc}
\hline Specimen & $\begin{array}{c}\sigma_{o} \\
(\mu \mathrm{m})\end{array}$ & $\begin{array}{c}S_{v}^{P^{P}} \\
\left(\mathrm{~mm}^{-1}\right)\end{array}$ & $\begin{array}{c}a^{P} \\
(\mu \mathrm{m})\end{array}$ \\
\hline PEARL1 & $0.20 \pm 0.03$ & $581 \pm 86$ & $4.16 \pm 0.70$ \\
PEARL2 & $0.06 \pm 0.01$ & $1432 \pm 60$ & $1.65 \pm 0.07$ \\
\hline
\end{tabular}

Table 5. Morphological characterisation of ferrite plus pearlite microstructure in MIXT steel.

\begin{tabular}{ccccc}
\hline Specimen & $\begin{array}{c}\sigma_{o} \\
(\mu \mathrm{m})\end{array}$ & $\begin{array}{c}S_{v}^{P P} \\
\left(\mathrm{~mm}^{-1}\right)\end{array}$ & $\begin{array}{c}a^{P} \\
(\mu \mathrm{m})\end{array}$ & $\begin{array}{c}\lambda \\
(\mu \mathrm{m})\end{array}$ \\
\hline MIXT1 & $0.15 \pm 0.02$ & $959 \pm 154$ & $2.50 \pm 0.50$ & $36 \pm 5$ \\
MIXT2 & $0.20 \pm 0.02$ & $728 \pm 144$ & $3.25 \pm 0.80$ & $43 \pm 4$ \\
MIXT3 & $0.25 \pm 0.04$ & $704 \pm 93$ & $3.40 \pm 0.40$ & $47 \pm 3$ \\
MIXT4 & $0.29 \pm 0.04$ & $871 \pm 106$ & $2.80 \pm 0.30$ & $49 \pm 10$ \\
\hline
\end{tabular}

Data for $\sigma_{\mathrm{o}}, S_{\mathrm{v}}^{\mathrm{PP}}$ and $a^{\mathrm{P}}$ for PEARL and MIXT steels are listed in Tables 4 and $\mathbf{5}$, respectively.

Likewise, Table 5 shows the mean free distance of pearlite for MIXT steel, $\lambda$, which is the mean edge-to-edge distance, along ramdom straight lines, between all possible pairs of pearlite nodules in a ferrite plus pearlite microstructure. The mean free distance of pearlite is ${ }^{13)}$ :

$$
\lambda=\frac{1-V_{\mathrm{P}}}{N_{\mathrm{L}}}
$$

where $V_{\mathrm{P}}$ is the volume fraction of pearlite and $N_{\mathrm{L}}$ is the number of pearlite interceptions per unit length of test line.

To evaluate the influence of heating rate and initial microstructure on the anisothermal formation of austenite, specimens with different initial microstructures (FERR, PEARL1-2 and MIXT1-4 specimens) were heated at a constant rate ranging from 0.005 to $100^{\circ} \mathrm{C} / \mathrm{s}$ in a Adamel Lhomargy DT1000 high-resolution dilatometer. The dimensional variations in the specimen are transmitted via an amorphous silica pushrod and measured by a linear variable differential transformer (LVDT) in a gas-tight enclosure enabling to test under vacuum or in an inert atmosphere. The DT1000 dilatometer is equipped with a radiation furnace for heating. The energy radiated by two tungsten filament lamps is focused on a cylindrical specimen of $2 \mathrm{~mm}$ in diameter and $12 \mathrm{~mm}$ in length by means of a bi-elliptical reflector. The advantages of this arrangement are the large instantaneous power transfer to a specimen of small mass, and the low thermal inertia ensuring an homogeneous temperature in the whole specimen during rapid heating. The temperature is measured with a $0.1 \mathrm{~mm}$ diameter chromelalumel (type K) thermocouple spot welded to the specimen in a central position. The high efficiency of heat transmission and the very low thermal inertia of the system ensure that the heating rates ranging from 0.003 to $200^{\circ} \mathrm{C} / \mathrm{s}$ remain constant.

The variation of the relative change of length as a func- 
tion of temperature $\left(\Delta L / L_{0}=f(T)\right)$ shown in the three dilatometric curves of Fig. 5, reproduces the contraction undergone by steels with different initial microstructures (ferrite, pearlite and ferrite plus pearlite) during continuous heating at $0.05^{\circ} \mathrm{C} / \mathrm{s}$. In all the cases, the formation of austenite takes place between the $A c_{1}$ and $A c_{3}$ temperatures which represent, respectively, the temperature at which the austenite formation starts and ends. The transformation start temperature $A c_{1}$ is defined as the temperature at which the linear thermal expansion, graphically represented by the $\Delta L / L_{0}=$ $f(T)$ function, first deviates from linearity. This behaviour is caused by the volume contraction associated with the austenite formation, which first compensates, and then reverses the normal expansion of the steel due to the increase in temperature. Location of the point at which the deviation occurs is obtained by extrapolating the linear portion of the thermal expansion curve. Likewise, transformation finish
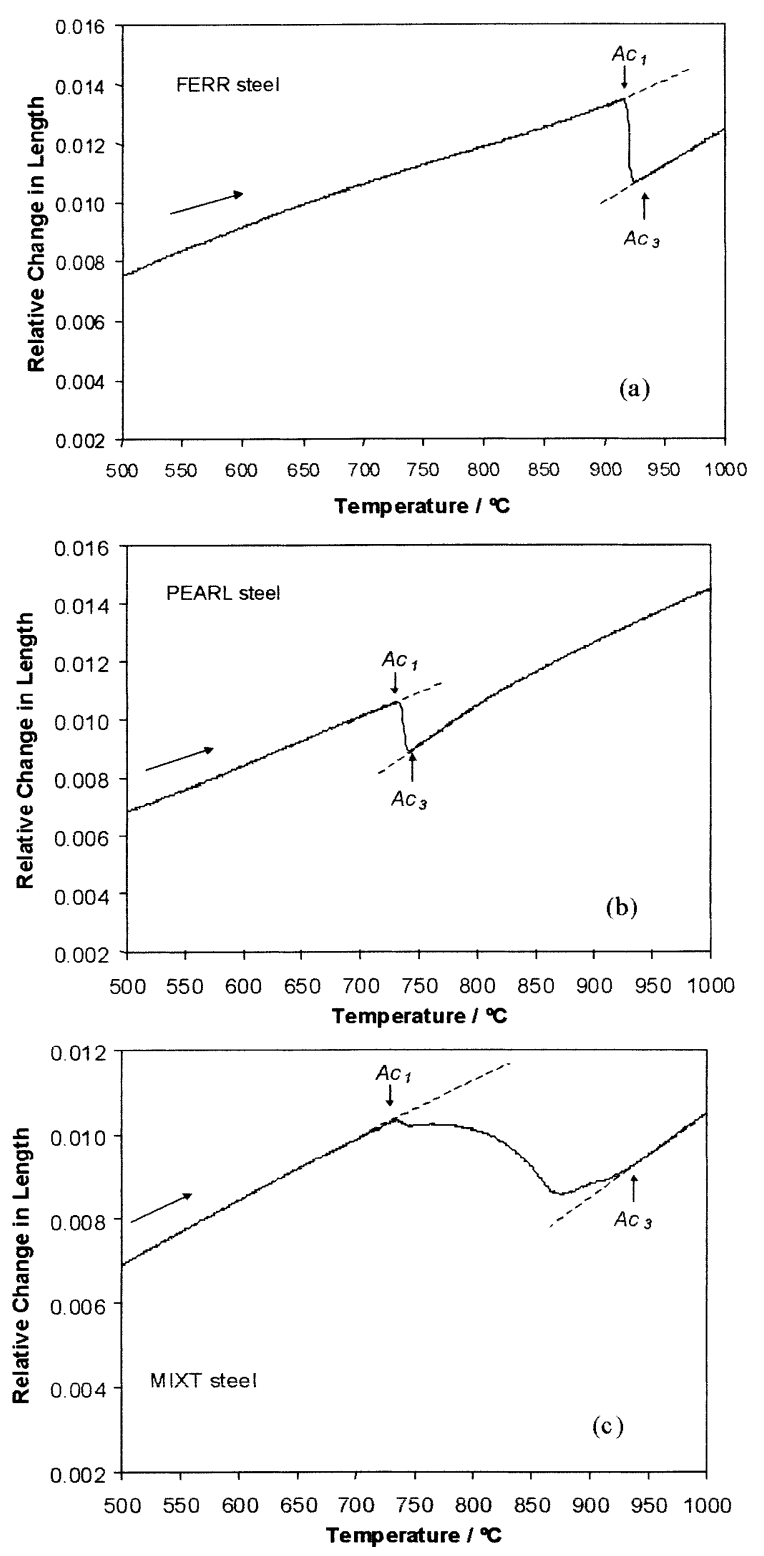

Fig. 5. Heating dilatometric curves of steels with different initial microstructures for a heating rate of $0.05^{\circ} \mathrm{C} / \mathrm{s}$ : (a) FERR steel with a full ferritic microstructure; (b) PEARL steel with a full pearlitic microstructure (PEARL2 specimen); (c) MIXT steel with a ferrite and pearlite microstructure (MIXT1 specimen). temperature $A c_{3}$ is determined by extrapolating the linear portion of the curve after transformation.

Figure 5 shows important differences among the three dilatometric curves. The heating dilatation curves shown in Figs. 5(a) and 5(b) display the contraction associated to the reaustenitisation of steels with a pure initial microstructure, fully ferritic and fully pearlitic microstructures, respectively. Experiments reveal clearly that austenite formation from pure ferrite and pure pearlite needs between 10 and $20^{\circ} \mathrm{C}$ to reach completion at a slow heating rate $\left(0.05^{\circ} \mathrm{C} / \mathrm{s}\right)$. On the other hand, dilatometric curve in Fig. 5(c) reproduces the contraction undergone by a steel with a ferrite and pearlite initial microstructure during continuous heating. In contrast to the austenitisation of pure initial microstructures, austenite formation from a mixture of ferrite and pearlite needs a wide range of temperature to reach completion, specially in low carbon steels, such as MIXT steel. Since pearlite dissolution is a much faster process than that of ferrite-to-austenite transformation, differentiation between pearlite dissolution and ferrite-to-austenite transformation may be detected in the heating dilatometric curves of low carbon steels. It is for that, the experimental curve in Fig. 5(c) shows an unusual well formed by contraction associated to the pearlite dissolution. ${ }^{5)}$ Interrupted heating tests at temperatures $10^{\circ} \mathrm{C}$ above and below $A c_{1}$ temperature confirmed that this anomaly effectively corresponds to the pearlite-to-austenite transformation. Authors reported in previous work ${ }^{5)}$ a significant effect of pearlite interlamellar spacing on the dilatometric contraction associated to the pearlite dissolution. The dilatometric anomaly associated with this transformation is eliminated as interlamellar spacing of pearlite increases. This effect is mainly caused by the influence of the interlamellar spacing on the austenite growth rate. Likewise, the small contraction after the relative change in length reaches to a minimum corresponds to the formation of austenite from some grains of ferrite that remains untransformed in the microstructure. As Datta et al. ${ }^{16)}$ found under isothermal conditions, those residual ferrite grains transform almost instantaneously due to a change in ferriteto-austenite transformation kinetics.

\section{Results and Discussion}

The influence of heating rate and initial microstructure on the anisothermal formation of austenite has been evaluated from the determination of the heating critical temperatures, $A c_{1}$ and $A c_{3}$, on dilatometric curves obtained at various heating rates in steels with ferrite and/or pearlite microstructures. The change of $A c_{1}$ and $A c_{3}$ temperatures with heating rate for FERR steel is shown in Fig. 6. Moreover, the effect of morphology of pearlite together with the heating rate on the critical temperatures is displayed on Figs. 7 and $\mathbf{8}$ for PEARL and MIXT steels, respectively.

The $A e_{1}$ and $A e_{3}$ temperatures in these figures (dotted and dashed lines) represent the start and end temperatures of austenite formation under equilibrium conditions, respectively. These temperatures has been determined from dilatometric curves obtained at a heating rate of $0.05^{\circ} \mathrm{C} / \mathrm{s}$. This is the rate normally used for considering quasi-equilibrium conditions. ${ }^{17)}$ In PEARL and MIXT steels, specimens with different morphology of pearlite were used for the de- 


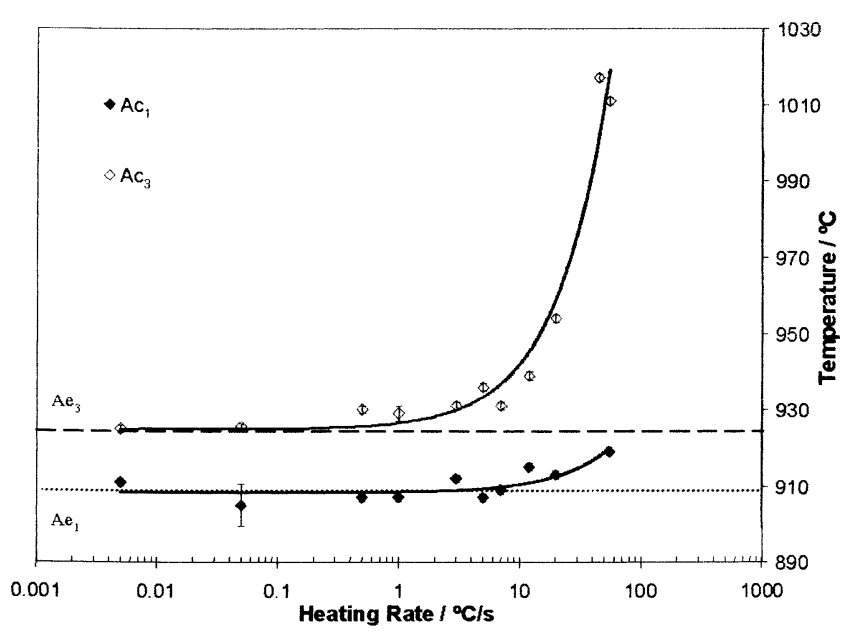

Fig. 6. Effect of heating rate on the $A c_{1}$ and $A c_{3}$ critical temperatures of a steel with a pure ferrite initial microstructure.

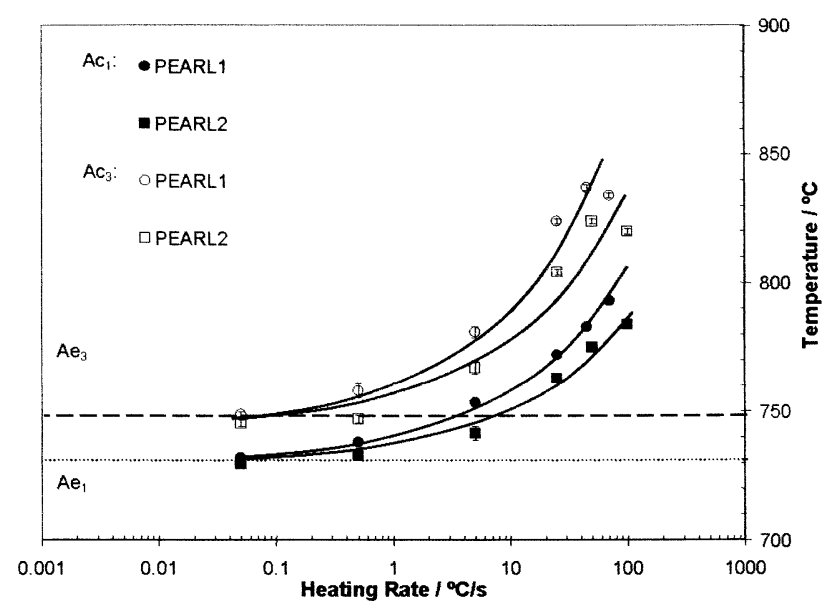

Fig. 7. Effect of heating rate and morphology on the $A c_{1}$ and $A c_{3}$ critical temperatures of a steel with a pure pearlite initial microstructure.

termination of these temperatures. Any difference between $A c$ and $A e$ temperatures will show the influence of heating rate and morphology on the kinetics of austenite formation. Solid lines in Figs. 6-8 represent a linear regression of the experimental results.

According to Figs. 7 and 8, independently of the morphology of their initial microstructure, the $A c_{1}$ and $A c_{3}$ temperatures in the eutectoid (PEARL) and low carbon (MIXT) steels scarcely rises with heating rate at slow and moderate rates of heating, i.e. up to about $1^{\circ} \mathrm{C} / \mathrm{s}$, whereas a stronger influence of heating rate on those critical temperatures is observed at higher rates. An increase of up to about $100^{\circ} \mathrm{C}$ is detected in the critical temperatures as heating rate is risen from 10 to $100^{\circ} \mathrm{C} / \mathrm{s}$ in both steels. For FERR steel, Fig. 6 suggests that the $A c_{1}$ temperature is almost insensitive to heating rate over the range studied, whereas $A c_{3}$ temperature follows a tendency similar to that found in PEARL and MIXT steels. In all the cases, it seems a reasonable approach to consider that $A c_{1}$ and $A c_{3}$ temperatures rises linearly with heating rate. The different linear regressions observed for different morphology of pearlite in PEARL and MIXT steels suggests that the elevation of the critical temperatures with heating rate is quite sensitive to morphological parameters. However, this influence is not
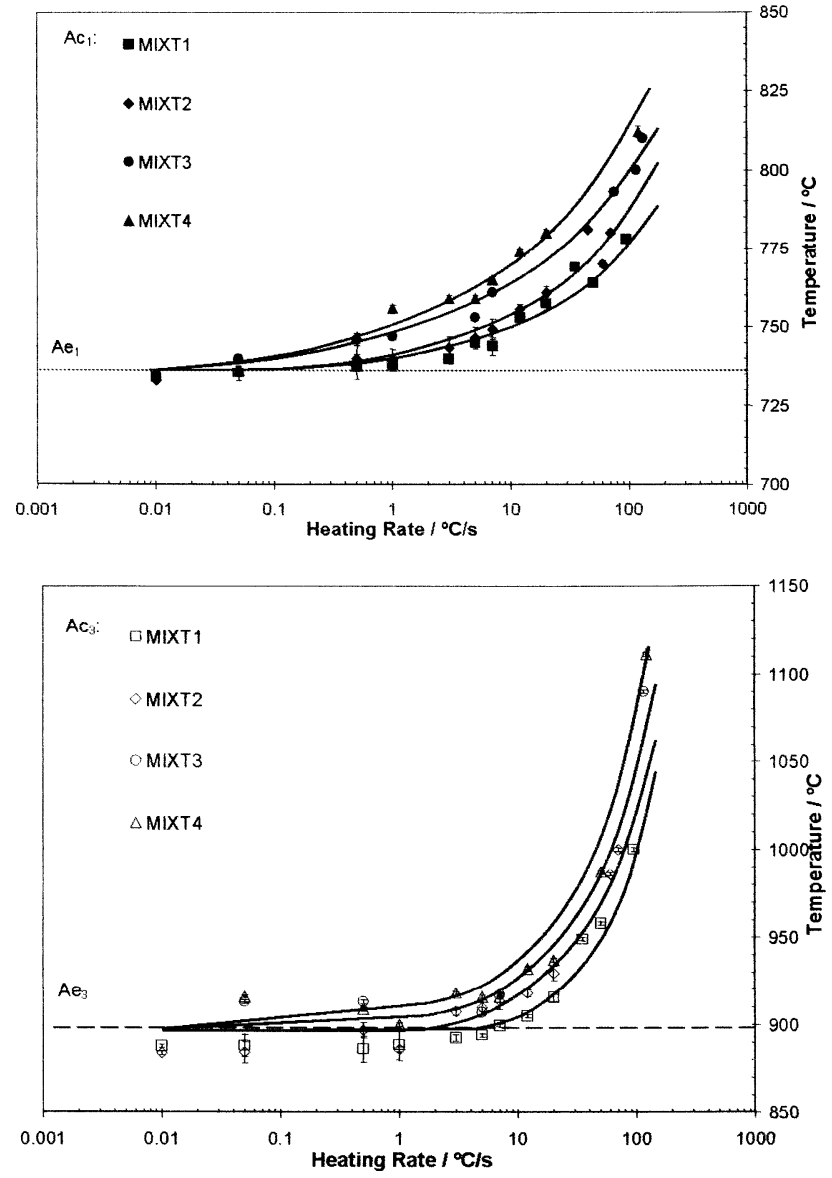

Fig. 8. Effect of heating rate and morphology of pearlite on the $A c_{1}$ and $A c_{3}$ critical temperatures of a steel with a ferrite and pearlite initial microstructure. (a) $A c_{1}$ temperature and (b) $A c_{3}$ temperature.

independent of the heating rate. It seems that the higher the heating rate is, the stronger the influence of morphology on the critical temperatures is.

The independence of the transformation start temperature from heating rate in FERR steel is consistent with a massive transformation that does not involve long range diffusion process. Speich and Szirmae estimated the maximum ferrite/austenite interface velocity as $0.016 \mathrm{~m} / \mathrm{s}$ for a $200 \mu \mathrm{m}$ ferrite grain diameter. ${ }^{18)}$ This is a very high velocity but still much less than that reported for diffusionless transformations, about $10^{3} \mathrm{~m} / \mathrm{s}^{19)}$ Formation of austenite from ferrite is well established to be a nucleation and growth process. The potential nucleation sites for austenite in pure iron are either in the matrix, at grain boundary faces, at grain boundary edges, or at grain corners. ${ }^{20)}$ All of them are exhausted early in the transformation ${ }^{21)}$ and the reaction is then further controlled by growth. The growth rate of austenite into ferrite, $G$, is given by ${ }^{22}$ :

$$
\begin{aligned}
G & =\frac{\delta v}{k T} \exp \left(-\frac{\Delta G_{\text {act }}}{k T}\right) \Delta g^{\alpha \rightarrow \gamma} \\
& =\frac{\delta v}{k T} \exp \left(\frac{\Delta S}{k}\right) \exp \left(\frac{-\Delta H}{k T}\right) \Delta g^{\alpha \rightarrow \gamma}\{T\}
\end{aligned}
$$

where $\delta$ is the boundary thickness, $v$ is the number of attempts to jump the boundary activation barrier per unit 
time, $k$ is the Boltzman constant, $T$ is the absolute temperature, $\Delta G_{\text {act }}$ is the free energy for the activated transfer atoms across the ferrite/austenite interface, $\Delta S$ is the entropy of activation per atom, $\Delta H$ is the enthalpy of activation per atom, and $\Delta g^{\alpha \rightarrow \gamma}$ is the Gibbs free energy difference per atom between the $\alpha$ and $\gamma$ phases. The values of $\Delta H$ and $v$ are uncertain but are generally assumed to be equal to the enthalpy of activation for grain boundary diffu$\operatorname{sion}^{23)}$ and to $k T / h$ (being $h$ Planck constant), respectively. The value of $\Delta S$ is also uncertain and may be negative or positive.

Figure 9 shows the Gibbs free energy change for the ferrite-to-austenite transformation, $\Delta g^{\alpha \rightarrow \gamma}$, for FERR steel. This energy has been obtained according to the thermodynamic calculations proposed by Aaronson et al. ${ }^{24,25)}$ and Kaufman et al. ${ }^{26)}$ In order to account for the effects of alloying elements into calculation, Zener factorisation of the free energy into magnetic and non-magnetic components has been performed. ${ }^{27)}$ The start temperature of the transformation corresponds to the temperature at which $\Delta g^{\alpha \rightarrow \gamma}=0$ i.e. the root of $\Delta g^{\alpha \rightarrow \gamma}$ function $\left(907^{\circ} \mathrm{C}\right.$ for FERR steel according to Fig. 9). This temperature is quite similar to the $A c_{1}$ temperatures measured in FERR steel over the heating rate range studied. Taking into account that the Gibbs free energy only depends on the chemical composition of the steel, the independence of the transformation start temperature from heating rate in FERR steel is then understood.

Regarding $A c_{3}$ temperature in this steel, kinetics theory ${ }^{28)}$ shows that a massive transformation such as ferrite-toaustenite transformation takes place almost instantaneously $\left(1^{\circ} \mathrm{C}\right)$, whereas the present experimental results revealed that this transformation needs between 20 and $100^{\circ} \mathrm{C}$ to reach completion depending on the heating rate. These behaviour only can be explained by some kinetic hindrance to transformation which is more significant, the higher the heating rate is.

As it has been pointed out, in PEARL and MIXT steel, the $A c_{1}$ and $A c_{3}$ temperatures rise linearly with heating rate over the studied range and they are quite sensitive to the morphology and dispersion state of pearlite. Figures 7 and 8 show that the heating critical temperatures are higher, the coarser the interlamellar spacing of the initial pearlite is, and the higher the heating rate is. Moreover, it seems that the heating critical temperatures increase as the mean free

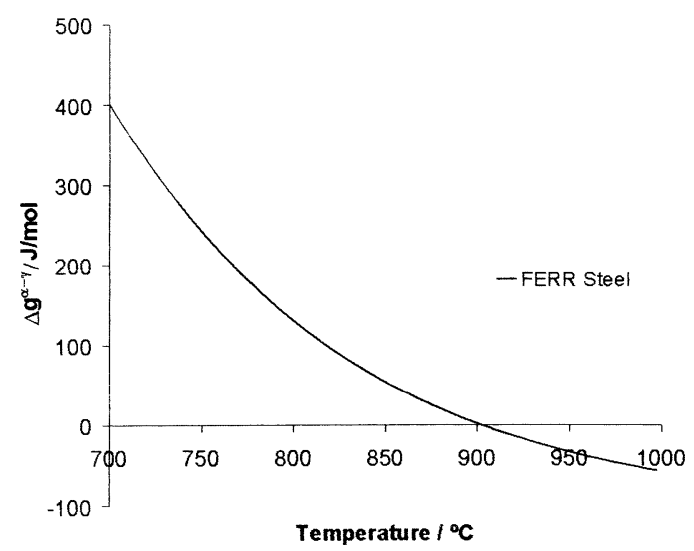

Fig. 9. Gibbs free energy change for $\alpha \rightarrow \gamma$ transformation in FERR steel. distance of pearlite nodules increases in the ferrite plus pearlite initial microstructure for MIXT steel (Fig. 8). The behaviour with the heating rate is not unusual since nucleation and growth kinetics are time-dependent phenomena. Likewise, this behaviour with change in the morphology and distribution state of pearlite appears logical since the rate at which the austenite formation can proceed depends on the rate at which carbon atom can be provided to the ferrite-austenite interface; this rate is very much dependent on the carbide shape, size and distribution.

- Determination of $A c_{1}$ and $A c_{3}$ Temperatures as a Function of Heating Rate and Pearlite Morphology for Steels with a Pearlite and Ferrite-Pearlite Initial Microstructure According to experimental results in Figs. 7 and 8, independently to the morphology of the initial microstructure, it seems reasonable to formulate a linear heating rate dependence of $A c_{1}$ and $A c_{3}$ temperatures as follows,

$$
A c_{1}=A e_{1}+f_{1}^{\text {morf }} \cdot \dot{T}
$$

and

$$
A c_{3}=A e_{3}+f_{3}^{\text {morf }} \cdot \dot{T}
$$

where $A e_{1}$ and $A e_{3}$ are the start and end critical temperatures of austenite formation under equilibrium conditions, respectively; $f_{1}^{\text {morf }}$ and $f_{3}^{\text {morf }}$ are the functions representing the dependence of $A c_{1}$ and $A c_{3}$ temperatures, respectively, on the initial microstructure (i.e. the different slopes observed for different morphology of pearlite in the linear regressions of the experimental data in Figs. 7 and 8); and $\dot{T}$ is the heating rate.

The first step of austenite formation in steels with a ferrite-pearlite starting microstructure consists of pearlite dissolution and growth of austenite into pearlite. ${ }^{29)}$ This process is controlled primarily by carbon diffusion in the austenite, with a diffusion distance about equal to the interlamellar spacing of the pearlite, unique morphology factor that affect the growth kinetics of austenite into pearlite. ${ }^{2)}$ However, the nucleation of austenite in pearlite may be also sensitive to morphological parameters such as the edge length of the pearlite colonies since the points of intersection of cementite with the edges of the pearlite colony are preferential sites for austenite nucleation into pearlite. ${ }^{1,2,9,18)}$ Subsequent steps of austenite growth into ferrite will be controlled by carbon diffusion in the austenite. ${ }^{2)}$ Those processes are not expected to be ferrite microstructure-sensitive, but might depend on the dispersion state of pearlite. Thus, $f_{1}^{\text {morf }}$ and $f_{3}^{\text {morf }}$ will depend on the morphology and dispersion state of pearlite. The determination of both functions will be analogous for steels with a pearlite and ferritepearlite initial microstructures, since the mean free distance of pearlite, or microstructural parameter that characterises the dispersion state of pearlite for a fully pearlitic microstructure is obviously zero.

Nucleation and growth processes under isothermal condition can be described in general using the Avrami's equation $^{30)}$ :

$$
V_{\gamma}=1-\exp \left(-\frac{\pi}{3} \dot{N} G^{3} t^{4}\right)
$$


where $V_{\gamma}$ represents the formed austenite volume fraction, $\dot{N}$ is the nucleation rate, $G$ is the growth rate and $t$ is the time. If the nucleation and growth rates do not depend on temperature and time, the time needed to transform a small volume fraction of austenite $\delta$ (about 0.01 ), at the starting point of transformation, will be expressed as follows:

$$
t(\delta)=\left[\frac{3 \ln (1-\delta)}{-\pi \dot{N} G^{3}}\right]^{1 / 4}
$$

The difference between $A c_{1}$ and $A e_{1}$ in continuous heating is approximately the product of $t(\delta)$ and the heating rate, $\dot{T}$. Therefore, the influence of the microstructure on $A c_{1}$ temperature can then be formulated as follows,

$$
A c_{1} \propto \frac{1}{\left(\dot{N} G^{3}\right)^{1 / 4}}
$$

Likewise, if the functions representing the influence of the microstructure on the nucleation and growth rates are named as $f_{\mathrm{N}}$ and $f_{\mathrm{G}}$, respectively, $f_{1}^{\text {morf }}$ will have the following general form,

$$
f_{1}^{\text {morf }} \propto \frac{1}{\left(f_{\mathrm{N}} f_{\mathrm{G}}^{3}\right)^{1 / 4}}
$$

As it was mentioned above, the nucleation of austenite inside pearlite takes place preferentially at the points of intersection of cementite with the edges of the pearlite colony. Approximating the pearlite colony as a truncated octahedron, the number of nucleation sites per unit volume is calculated as $N_{\mathrm{C}} \approx 1 /\left(\left(a^{\mathrm{P}}\right)^{2} \sigma_{\mathrm{o}}\right)$, where $a^{\mathrm{P}}$ is the edge length of the pearlite colony and $\sigma_{\mathrm{o}}$ is the interlamellar spacing. ${ }^{15)}$ It seems reasonable then to assume the function $f_{\mathrm{N}}$ in Eq. (9) to be proportional to the number of nucleation sites per unit volume i.e. $f_{\mathrm{N}} \propto\left(N_{\mathrm{C}}\right)^{i}$, being $i$ a constant. ${ }^{9)}$ Roosz et al. ${ }^{9)}$ investigated all the three cases of microstructure dependence for $i=1,2$ and 3, and they found that their measured values of austenite volume fraction were best described with $i=2$.

On the other hand, austenite nuclei in pearlite grow when carbon atoms are transported by diffusion to the ferrite/austenite boundary from the austenite/cementite boundary through the austenite and from the ferrite/cementite boundary through the ferrite, resulting in a transformation of the ferrite lattice to an austenite lattice. ${ }^{31)}$ As in the case of the reverse transformation (austenite-to-pearlite transformation), the growth rate of austenite in pearlite is believed to be controlled by the volume diffusion of carbon in the growing phase, ${ }^{2,18)}$ and it is assumed that the effective diffusion distance is approximately equal to the interlamellar spacing of pearlite. Hillert et l $^{31)}$ studied the isothermal formation of austenite from a mixture of ferrite and pearlite, and suggested that the expression of the austenite growth rate in pearlite could have the general form $G \propto 1 / \sigma_{\mathrm{o}}$. Thus, the function $f_{\mathrm{G}}$ in Eq. (9) can be expressed as $f_{\mathrm{G}} \propto 1 / \sigma_{\mathrm{o}}$.

Therefore the function $f_{1}^{\text {morf }}$ in Eq. (9) that expresses the microstructure dependence of the start austenite formation temperature in steels with a pearlite and ferrite-pearlite initial microstructures, can be formulated as $f_{1}^{\text {morf }} \propto\left(\sigma_{\mathrm{o}}^{3} / N_{\mathrm{C}}^{2}\right)^{1 / 4}$.
The best linear fitting between the different slopes of the solid lines in Figs. 7 and 8, and the complex morphological parameter $\left(\sigma_{\mathrm{o}}^{3} / N_{\mathrm{C}}^{2}\right)^{1 / 4}$ has the following form,

$$
f_{1}^{\text {morf }}=\frac{2}{5} \cdot\left(\frac{\sigma_{\mathrm{o}}^{3}}{N_{\mathrm{C}}^{2}}\right)^{1 / 4}+\frac{1}{2}
$$

and thus Eq. (4) can be rewrite as follows,

$$
\begin{aligned}
A c_{1} & =A e_{1}+\left[\frac{2}{5} \cdot\left(\frac{\sigma_{\mathrm{o}}^{3}}{N_{\mathrm{C}}^{2}}\right)^{1 / 4}+\frac{1}{2}\right] \cdot \dot{T} \\
& =A e_{1}+\frac{2}{5} \cdot\left(\frac{\sigma_{\mathrm{o}}^{3}}{N_{\mathrm{C}}^{2}}\right)^{1 / 4} \cdot \dot{T}+\frac{1}{2} \cdot \dot{T}
\end{aligned}
$$

with $\sigma_{\mathrm{o}}$ in $\mu \mathrm{m}$ and $N_{\mathrm{C}}$ in $\mu \mathrm{m}^{-3}$.

Following the above reasoning, the microstructure dependence of $A c_{3}$ temperature can be also determined. In general, it appears reasonable to assume that the temperature at which the transformation is completed must depend mainly on the growth rate of the transformation since nucleation sites saturate early in the reaction and the reaction is then controlled by growth. This assumption is adequate for austenite formation in both pearlitic and ferrite plus pearlite steels, since in both type of steels, the transformation during heating occurs within a finite temperature range. In the case of PEARL steel, it has been found that austenite formation occurs in a temperature range of 20 or $50^{\circ} \mathrm{C}$ depending on the morphology of pearlite and the heating rate. This is a rapid transformation, but not instantaneous. It seems reasonable then to consider all of the nucleation sites exhausted lately in the transformation and the reaction controlled by growth in both PEARL and MIXT steels. In this case, the reaction law in Eq. (6) can be expressed with an exponent of 1 in time in Avrami's equation, ${ }^{20)}$

$$
V_{\gamma}=1-\exp (-K G t)
$$

where $K$ is a constant that contains the number of nucleation sites for austenite and $G$ is the growth rate of austenite. The influence of the microstructure on $A c_{3}$ temperature can then be formulated in the same way than Eq. (8),

$$
A c_{3} \propto \frac{1}{K G}
$$

The growth of austenite in pearlite, or first step of austenite formation in steels with a ferrite-pearlite starting microstructure, is primarily controlled by the volume diffusion of carbon atom in the austenite with a diffusion distance about equal to the interlamellar spacing of the pearlite. After completion of pearlite disolution, austenite grows into the surrounding ferrite. The growth rate of austenite in ferrite is mainly controlled by carbon diffusion through the austenite. ${ }^{2)}$ This process is not a ferrite microstructure-sensitive. The growth rate of austenite in ferrite only depends on the chemical composition of the steel through the diffusion coefficient of carbon that control the movement of the ferrite/austenite interface. Therefore, the influence of the microstructure on the growth kinetics of austenite can then 
be formulated as $f_{\mathrm{G}} \propto 1 / \sigma_{\mathrm{o}}$ for a steel with a pearlite and ferrite plus pearlite initial microstructure. ${ }^{31)}$ However, the progress of ferrite-to-austenite transformation depends on the amount of pearlite in the initial microstructure (i.e. volume fraction of pearlite, $V_{\mathrm{P}}$ ) and its dispersion state since the nucleation sites of austenite are in pearlite. The number of nucleation sites for austenite $(K)$ depends on the surface area per unit volume of pearlite nodules $\left(S_{\mathrm{v}}\right)$. Therefore, the microstructure dependence of $A c_{3}$ temperature, $f_{3}^{\text {morf }}$, will depend on the volume fraction of pearlite, its morphology and, on the surface area per unit volume of pearlite in a ferrite plus pearlite initial microstructure:

$$
f_{3}^{\text {morf }}=f\left(V_{\mathrm{P}}, \sigma_{\mathrm{o}}, \frac{1}{S_{\mathrm{v}}}\right)
$$

In this sense, the following general form for $f_{3}^{\text {morf }}$ is proposed:

$$
\begin{aligned}
f_{3}^{\text {morf }} & \propto V_{\mathrm{P}}^{2}\left[\sigma_{\mathrm{o}}+\left(\frac{1-V_{\mathrm{P}}}{S_{\mathrm{v}}}\right)\right] \\
& =V_{\mathrm{P}}^{2}\left[\sigma_{\mathrm{o}}+\left(\frac{1-V_{\mathrm{P}}}{4 N_{\mathrm{L}}}\right)\right]=V_{\mathrm{P}}^{2}\left(\sigma_{\mathrm{o}}+\frac{\lambda}{4}\right) \ldots .
\end{aligned}
$$

where $V_{\mathrm{P}}$ is the volume fraction of pearlite, $N_{\mathrm{L}}$ is the number of pearlite interceptions per unit length of test line, ${ }^{13)}$ and $\lambda$ is the mean free distance of pearlite. In the case of a fully pearlitic microstructure $f_{3}^{\text {morf }} \propto \sigma_{\mathrm{o}}$.

The best linear fitting between the slopes observed for different morphology of pearlite in the linear regressions of the $A c_{3}$ experimental data in Figs. 7 and 8, and the morphological parameter $\sigma_{\mathrm{o}}$ has the following form,

$$
f_{3}^{\text {morf }}=4 V_{\mathrm{P}}^{2}\left(\sigma_{\mathrm{o}}+\frac{\lambda}{4}\right)+\frac{1}{2}
$$

and thus Eq. (5) can be rewrite as follows,

$$
\begin{aligned}
A c_{3} & =A e_{3}+\left[4 V_{\mathrm{P}}^{2}\left(\sigma_{\mathrm{o}}+\frac{\lambda}{4}\right)+\frac{1}{2}\right] \cdot \dot{T} \\
& =A e_{3}+4 V_{\mathrm{P}}^{2}\left(\sigma_{\mathrm{o}}+\frac{\lambda}{4}\right) \cdot \dot{T}+\frac{1}{2} \cdot \dot{T}
\end{aligned}
$$

with $\sigma_{\mathrm{o}}$ and $\lambda$ in $\mu \mathrm{m}$.

Resembling experimental results, Eqs. (11) and (17) suggest that an increase in the heating rate leads to an elevation of the start and finish temperatures of austenite formation independently of the morphology of pearlite, whereas the morphological parameters of pearlite only affect the critical temperatures at high enough heating rates. Thus, the heating critical temperatures can be factorised into three intrinsic components: the influence of the composition of the steel, the effect of the heating rate and the convoluted effect of microstructure and heating rate.

Comparison between experimental and calculated $A c_{1}$ and $A c_{3}$ values using Eqs. (11) and (17) in PEARL and MIXT steels at various heating rates and for specimens with different initial morphology of pearlite is shown in

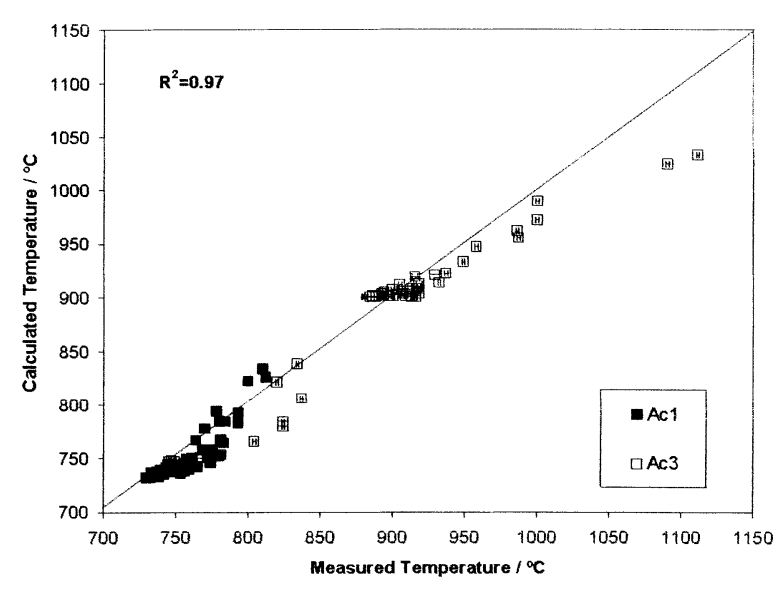

Fig. 10. Comparison of experimental and calculated $A c_{1}$ and $A c_{3}$ critical temperatures of steels with a pearlite and ferritepearlite initial microstructures.

Fig. 10. Points lying on the line of unit slope show perfect agreement between experimental and calculated values. The accuracy of the calculations is quantified by $R^{2}$. The $A c_{1}$ and $A c_{3}$ values calculated from the equations proposed in this work are in good agreement (with an accuracy of $97 \%$ in square correlation factor) with the corresponding experimental results.

\section{Conclusions}

(1) The influence of heating rate and initial microstructure on the anisothermal formation of austenite has been evaluated from the determination of the heating critical temperatures, $A c_{1}$ and $A c_{3}$, on dilatometric curves obtained at various heating rates in steels with ferrite and/or pearlite initial microstructure. In all the cases studied, it seems that $A c_{1}$ and $A c_{3}$ temperatures rises linearly with heating rate, except for steels with a pure ferrite initial microstructure, where the $A c_{1}$ temperature is almost insensitive to heating rate over the range studied. This independence of the transformation start temperature from heating rate is consistent with a massive transformation that does not involve long range diffusion process.

(2) Experimental results in steels with a pearlite and ferrite-pearlite initial microstructures show that that elevation of the critical temperatures with heating rate is quite sensitive to the morphology of pearlite. This influence is not independent of the heating rate. It seems that the higher the heating rate is, the stronger the influence of morphology on the critical temperatures is. The elevation of the critical temperatures with the heating rate in these steels is not unusual since nucleation and growth kinetics are time-dependent phenomena. Likewise, the behaviour with the morphology of pearlite is explained by the fact that the rate at which the austenite formation can proceed depends on the rate at which carbon can be available in the ferrite. This rate is very much dependent on the pearlite morphology and its dispersion state.

(3) This experimental study and the knowledge of the mechanisms that control the austenite formation process have allowed to establish the variables that most directly influence this reaction in steels with pearlite and ferritepearlite initial microstructures. Those are the heating rate 
and the morphological parameters that characterise the morphology of pearlite in both microstructures: the mean true interlamellar spacing and the area per unit volume of the pearlite colonies interface in pearlitic steels, together with the volume fraction of pearlite and the mean free distance of pearlite in ferrite plus pearlite initial microstructures.

(4) Finally, two equations have been found for the determination of the start $\left(A c_{1}\right)$ and $\left(A c_{3}\right)$ finish temperatures of austenite formation. In these equations, the heating critical temperatures are factorised into three intrinsic components: the influence of the composition of the steel, the effect of the heating rate and the convoluted effect of microstructure and heating rate.

\section{Acknowledgements}

Authors acknowledge financial support from the Ministerio de Ciencia y Tecnología (MCyT) (ProyectoPETRI 95-0436-OP). Sidenor and CEIT are thanked for their collaboration in this project. F. G. Caballero would like to thank the Dirección General de Investigación de la Comunidad Autónoma de Madrid (CAM) for the financial support in the form of a postdoctoral research grant.

\section{REFERENCES}

1) C. I. García and A. J. DeArdo: Metall. Trans. A, 12A (1981), 521.

2) G. R. Speich, V. A. Demarest and R. L. Miller: Metall. Trans. A, 12A (1981), 1419

3) M. M. Souza, J. R. C. Guimaraes and K. K. Chawla: Metall. Trans. $A$, 13A (1982), 575.

4) X.-L. Cai, A. J. Garrat-Reed and W. S. Owen: Metall. Trans. A, 16A (1985), 543.

5) C. García de Andrés, F. G. Caballero and C. Capdevila: Scri. Mater., 38 (1998), 1835

6) G. Krauss: Steels: Heat Treatment and Processing Principles, ASM International, Metals Park, OH, (1989), 274.
7) A. Gustavsson, D. L. Mcdowell, A. Melander and M. Larsson: Inst. Metallforsk. Forsk. Rapp., 88 (1994), 3145.

8) V. L. Gadgeel: Tool Alloy Steels, 28 (1994), 17.

9) A. Roosz, Z. Gacsi and E. G. Fuchs: Acta Metall., 31 (1983), 509.

10) L. Gavard, H. K. D. H. Bhadeshia, D. J. C. MacKay and S. Suzuki: Mater. Sci. Technol., 12 (1996), 453.

11) C. A. L. Bailer-Jones, H. K. D. H. Bhadeshia and D. J. C. MacKay: Mater. Sci. Technol., 15 (1999), 287.

12) G. F. Vander Voort: Metallography. Principles and Practice, McGraw-Hill, New York, (1984), 427.

13) E. E. Underwood: Quantitative Stereology, Addison-Wesley Publishing Co, Reading, (1970), 73.

14) S. A. Saltykov: Stereometric Metallography, Metallurgizdat, Moscow, (1958), 267.

15) R. T. De Hoff and F.H. Rhines: Quantitative Stereology, McGrawHill, New York, (1968), 93.

16) D. P. Datta and A. M. Gokhale, Metall. Trans. A, 12A (1981), 443.

17) C. García, L. F. Alvarez and M. Carí: Weld. Int., 6 (1992), 612.

18) G. R. Speich and A. Szirmae: Trans. TMS-AIME, 245 (1969), 1063.

19) R. F. Bunshah and R. F. Mehl: Trans. TMS-AIME, 197 (1953), 1251.

20) J. W. CAHN: Acta Metall., 4 (1956), 449.

21) S. F. Dirnfeld, B. M. Korevaar and F. Van’t Spijker: Metall. Trans., 5 (1974), 1437.

22) J. W. Christian: The Theory of Transformations in Metals and Alloys. Part 1, Pergamon Press, Oxford, (1975), 19.

23) P. Shewmon: Diffusion in Solid, McGraw-Hill, New York, (1963), 166.

24) H. I. Aaronson, H. A. Domian and G. M. Pound: Trans. TMS-AIME, 236 (1966), 753.

25) H. I. Aaronson, H. A. Domian and G. M. Pound: Trans. TMS-AIME, 236 (1966), 768

26) L. Kaufman, E. V. Clougherty and R. J. Weiss: Acta Metall., 11 (1963), 323.

27) C. Zener: Trans. AIME, 167 (1946), 550.

28) F. G. Caballero, C. Capdevila and C. García de André: Mater. Sci. Technol., 17 (2001), 1114.

29) F. G. Caballero, C. Capdevila and C. García de André: ISIJ Int., 41 (2001), 1093.

30) M. Avrami: J. Chem. Phys., 8 (1940), 212.

31) M. Hillert, K. Nilsson, and L. E. Torndahl: J. Iron Steel Inst., 209 (1971), 49. 